\title{
ВЛИЯНИЕ АУДИТА ЭФФЕКТИВНОСТИ НА РАЦИОНАЛИЗАЦИЮ РЕШЕНИЙ КРЕДИТНЫХ ОРГАНИЗАЦИЙ
}

\section{IMPACT OF PERFORMANCE AUDITS ON THE RATIONALIZATION OF CREDIT INSTITUTIONS' DECISIONS \\ Al-Saadi Mohanad Raheem Salim}

Summary: The quality of decisions made by credit organizations allows such organizations to adapt to opportunities and threats coming from outside, to maintain a balance of private and public interests while protecting the rights of depositors and creditors, as well as to influence risk-taking and compliance with mandatory requirements and regulations by the credit organization. The risks taken by credit institutions are the main determinants of the decision-making process of such organizations. In the article, the author examines the relationship between decisionmaking and the results of an audit of the effectiveness of certain types of risk and concludes that the most effective tool for analyzing and accounting for risks and optimal responses of credit institutions to changing market conditions is an efficiency audit, since an efficiency audit allows evaluating the structure of assets and liabilities taking into account the totality of actual data provided by relevant information, as well as conduct comprehensive monitoring of the external and internal environment in order to effectively use the opportunities that open up.

Keywords: performance audit, decision-making, credit institutions, leverage, balance sheet management, equity adequacy.

\author{
Аль-Саади Моханад Рахим Салим \\ Аспирант, ФГБОУ ВО «Российский экономический \\ университет имени Г.В. Плеханова» \\ mmhhdd39@yahoo.com
}

Аннотация: Качество принимаемых кредитными организациями решений позволяет таким организациям адаптироваться к возможностям и угрозам, исходящим извне, соблюдать баланс частных и публичных интересов при защите прав вкладчиков и кредиторов, а также влиять на принятие рисков и соблюдение кредитной организацией обязательных требований и нормативов. Риски, принимаемые кредитными организациями, являются основными детерминантами процесса принятия такими организациями решений. В статье автор рассматривает взаимосвязь принятия решений с результатами аудита эффективности отдельных видов риска и делает вывод о том, что наиболее действенными инструментом для анализа и учета рисков и оптимальных реакций кредитных организаций на изменяющиеся рыночные условия является аудит эффективности, поскольку аудит эффективности позволяет оценивать структуру активов и пассивов с учетом совокупности фактических данных, представленных соответствующей информацией, а также проводить комплексный мониторинг внешней и внутренней среды в целях эффективного использования открывающихся возможностей.

Ключевые слова: аудит эффективности, принятие решений, кредитные организации, леверидж, управление балансов, достаточность собственных средств.

(Центральным Банком Российской Федерации), кредиторами и финансовыми рынками. При этом риск, принимаемый кредитными организациями, является одним из основных детерминантов процесса принятия такими организациями решений. Для кредитной организации риск является не только ограничением, наложенным на множество допустимых стратегий.

Как отмечается в специализированной литературе, кредитные организации, будучи инвестиционными компаниями, действуют в режиме балансирования риска и вознаграждения [8], при этом в соответствии с принципами управления активами и пассивами они стремятся максимизировать скорректированную на риск доходность капитала (или на скорректированный на риск капитал) в рамках рыночных и регуляторных ограничений $[5]$.

Исходя из сказанного, можно сделать обоснованный вывод о том, что выбор кредитной организацией правильного инвестиционного пути требует большого количества инструментов управления рисками и объек- 
тивной оценки таких рисков. Такую оценку как раз и предоставляет аудит эффективности, основными задачами которого является определение зон потери контроля над рисками, оценка эффективности существующей системы риск-менеджмента характеру и объему совершаемых операций, а также выработка рекомендаций по ее совершенствованию. Объектами аудита эффективности являются кредитный риск, риск ликвидности, рыночный риск, операционный риск, стратегический риск и другие риски.

Взаимосвязь принятия решений с аудитом эффективности обусловлена теми возможностями, которые открываются перед лицами, принимающими решение, после получения результатов аудита эффективности. С одной стороны, кредитные организации, являясь профессиональными участниками рынка, предсказуемо реагируют на предполагаемые рыночные потрясения и без проведения аудита эффективности. Но, с другой стороны, именно результаты аудита эффективности позволяют выявить, есть ли предпосылки к увеличению того или иного риска. Например, увеличение кредитного риска или стоимости финансирования неизменно повлечет за собой более значительное сокращение кредитных портфелей при одновременном ухудшении рыночных условий. Поэтому результаты аудита эффективности влияют на направление и качество принимаемых решений, особенно в неблагоприятных рыночных условиях. Отсюда можно назвать аудит эффективности инструментом для анализа теоретически оптимальных реакций кредитных организаций на изменяющиеся рыночные условия. Аудит эффективности может использоваться также в качестве дополнительного инструмента при оценке банковского канала денежно-кредитной политики (например, шоков предложения кредитов, связанных с сокращением доли заемных средств).

Описание самого процесса принятия решений в кредитных организациях затруднительно, поскольку не до конца понятно, как руководство кредитных организаций банков реагирует на ограничения, накладываемые, например, акционерами, или как кредиторы воспринимают истинное финансовое положение кредитной организации и как все вышеобозначенные субъекты доверяют друг другу. По мнению автора статьи, можно лишь составить представление о том, какими свойствами должна обладать структура принятия рациональных решений. Примечательно, что она отражает некоторые особенности банковской сферы, которые препятствуют адекватному проектированию механизмов в процессе принятия кредитными организациями решений.

Одна из важных проблем, которую позволяет решать аудит эффективности, позволяя принимать рациональные решения, связана с долговым и капитальным финансированием кредитных организаций. В зарубежной литературе такая проблема именуется «асимметричной информацией» [9]. Проблемы, вытекающие из этой асимметрии, решаются с помощью требования к кредитным организациям иметь достаточный собственный капитал. Если по результатам аудита эффективности выяснится, что требования к достаточности собственных средств соблюдаются, то делается однозначный вывод о том, что смещение рисков снижается и кредитная организация может принять решение сохранить соответствующий объем необеспеченных депозитов.

Оптимальный уровень капитала связан с конкурирующими силами дисциплинирующих эффектов финансирования через эмиссию долговых обязательств и смещающих риски последствий чрезмерного соотношения вложений капитала в ценные бумаги с фиксированным и нефиксированным доходом (левериджа). Более высокий уровень долгового финансирования побуждает незастрахованных кредиторов внимательно следить за управленческими действиями, то есть за кредитным качеством кредитов и ценных бумаг в их портфелях.

В противоположность этому недостаточный уровень собственного капитала кредитной организации может быть стимулом для решений, связанных с принятием кредитной организацией на себя чрезмерного риска, что, в свою очередь, может увеличить стоимость опциона на акции с базовыми активами кредитной организации. При наличии обязательного страхования (как и любых других форм страхования) смещение рисков еще более выражено, поскольку кредитные организации, как правило, становятся более заемными. В целом же феномен смещения риска требует минимального размера собственных средств (капитала) кредитной организации, а аудит эффективности в части оценки размера собственных средств (капитала) кредитной организации позволяет принимать наиболее рациональные решения.

На практике как правило кредитные организации сохраняют размер капитала выше нормативных минимумов, поскольку способность поглощения разумных потерь может иметь положительные сигнальные эффекты для заемщиков. Высокий размер капитала повышает уровень мониторинга заемщиков, и это хорошо для заемщиков, поскольку увеличивает доходность их проектов, финансируемых кредитными организациями. Кредитные организации с хорошей капитализацией имеют высокую вероятность выживания, что способствует улучшению мониторинга и улучшению кредитного качества кредитных портфелей.

Следующей важной проблемой, которую позволяет решить аудит эффективности, является управление балансом кредитной организации. При принятии кредитной организацией решений неизбежно возникают вопросы о том, как максимизировать прибыль при учете 
минимизации риска ликвидности, и о том, как обеспечить приемлемый уровень ликвидности или минимизацию вероятности дефицита ликвидности. Подход, основанный на оптимизации структуры баланса кредитной организации, может быть применен в качестве эталона для рациональных управленческих решений. В настоящее время если кредитные организации корректируют свои балансы в ответ на шоки, является очевидностью. Обычно это происходит путем продажи заранее определенных классов активов. Таким образом, кредитные организации ориентируются на свой коэффициент левериджа и стараются сохранить продуктовую структуру своих активов. Однако не все методологии кредитных организаций по принятию решения в части корректировки баланса являются правильным, поскольку такие методологии не учитывают отдельные факторы, которые могут быть выявлены при проведении аудита эффективности.

Аудит эффективности при принятии решений в части управления балансом кредитной организации позволяет избежать риска манипуляций с параметрами, которые могут подразумевать чрезмерно оптимистичные результаты, не основанные на рисковых факторах. Сама по себе модель категорий активов и пассивов довольно сложна даже в самых агрегированных условиях. Тем не менее, аудит эффективности позволяет выявить фундаментальные различия в том, как статьи баланса влияют на общие доходы и расходы кредитной организации.

Рассмотрим, как это происходит на практике. Каждая кредитная организация имеет определенную структуру активов и пассивов в начале инвестиционного горизонта. В течение следующего периода кредитная организация принимает решение о реструктуризации части состава активов. Однако не все категории разрешены к ликвидации - кредитный портфель сохраняется до погашения, поэтому сокращение его объема может произойти только в результате частичного реинвестирования части кредитных пулов со сроком погашения. Общая балансовая сумма кредитных организаций соответствует определенному объему пассивов и собственного капитала, которые формируются в зависимости от воздействия внешних факторов, находящихся за пределами усмотрения кредитных организаций и не учитываются методиками управления балансами. Общая балансовая сумма может измениться, если только обязательства не будут полностью пролонгированы или капитальная база сократится. При проведении аудита эффективности и выявлении дополнительных факторов, влияющих на принятие решений, реструктуризация состава активов будет основана на оптимизации скорректированного на риск дохода и будет учитывать параметры, определяющие эффективность наиболее важных классов активов и пассивов. Иными словами, решения, принимаемые в части решения проблемы управления балансом, будут более рациональными и основанными на рисковых факторах, а не на методике управления балансом, не подкрепленной фактическими данными.

Подводя итог, необходимо отметить, что такой сложный институт, как кредитная организация, может быть не способен быстро реагировать на неожиданные изменения рыночной конъюнктуры, поскольку выбор правильного инвестиционного пути требует большого количества инструментов управления рисками и объективной оценки таких рисков. Аудит эффективности является наиболее действенными инструментом для анализа оптимальных реакций кредитных организаций на изменяющиеся рыночные условия, поскольку его результаты влияют на направление и качество принимаемых решений.

\section{ЛИТЕРАТУРА}

1. Федеральный закон от 02.12.1990 № 395-1 «0 банках и банковской деятельности» (с изм. и доп., вступ. в силу с 14.06.2020) // Собрание законодательства РФ. - 1996. - 6. - Ст. 492.

2. Бабичева Ю. Внутрибанковский аудит в обеспечении транспарентности кредитных организаций // Вестник Института экономики РАН. - 2013. - №2. C.80-86.

3. Бузмакова Марина Владимировна. Методика оценки аудиторского риска при внутреннем аудите расчетных операций коммерческого банка// Символ науки. - 2016. - № 5 (1). - С. 59-67.

4. Пашков Р., Юденков Ю. Проблемы реализации структурной концепции управления банком // Бухгалтерия и банки. - 2019. - № 5 . - С. 45 - 48.

5. Пашков Р., Чечелев Ю. Оценка регуляторного риска в банке // Бухгалтерия и банки. - 2020. - № 3. - С. 41 - 51.

6. Подколзина Э.А., Кузьмичева И.А. Система управления банковскими рисками // Science Time. - 2014. - №12 (12). - С.415-421

7. артарашвили Т.Т. Аудит эффективности управления рисками коммерческого банка // Международный бухгалтерский учет. - 2010. - №6. - С.43-49.

8. Miles D., Yang J., and Marcheggiano G.. Optimal bank capital. Discussion Papers 31, Mone-tary Policy Committee Unit, Bank of England, April 2011.

9. Kruger M. A goal programming approach to strategic bank balance sheet management, 2011. Электронный ресурс. Режим доступа: https://support.sas.com/ resources/papers/proceedings11/024-2011.pdf (дата обращения 30.09.2020 г.).

() Аль-Саади Моханад Рахим Салим (mmhhdd39@yahoo.com).

Журнал «Современная наука: актуальные проблемы теории и практики» 